\title{
3 Research Square

\section{Liquefaction Potential Determination and Hazard Mapping Based on Standard Penetration Tests in Long Beach and Tuzla Regions of Cyprus}

\section{Onur Selcukhan}

Middle East Technical University Northern Cyprus Campus: Orta Dogu Teknik Universitesi - Kuzey Kibris Kampusu

Abdullah Ekinci ( $\nabla$ ekincia@metu.edu.tr)

Middle East Technical University https://orcid.org/0000-0002-6787-9983

\section{Research Article}

Keywords: liquefaction, hazard mapping, standard penetration testing, factor safety coefficient

Posted Date: December 8th, 2021

DOI: https://doi.org/10.21203/rs.3.rs-1077123/v1

License: (c) (i) This work is licensed under a Creative Commons Attribution 4.0 International License.

Read Full License 


\title{
Liquefaction Potential Determination and Hazard Mapping Based on Standard Penetration Tests in Long Beach and Tuzla regions of Cyprus
}

\author{
Onur Selcukhan ${ }^{1}$ and Abdullah Ekinci ${ }^{2 *}$ \\ 1 MSc Student, Civil Engineering Program, Middle East Technical University, North Cyprus Campus, \\ Kalkanli, Guzelyurt, Northern Cyprus, TR-10, Turkey: E-mail: onur.selcukhan@metu.edu.tr \\ 2 Assistant Professor, Civil Engineering Program, Middle East Technical University, North Cyprus Campus, \\ Kalkanli, Guzelyurt, Northern Cyprus, TR-10, Turkey: E-mail: ekincia@ metu.edu.tr \\ * Correspondence: ekincia@ metu.edu.tr; Tel.: +90 5428881440
}

\section{Abstract}

This study proposes an improved and precise liquefaction risk index for the evaluation and translation of outcomes into maps to establish susceptible liquefiable areas. Cyprus is the third largest and populated island in the Mediterranean Sea, which is rapidly expanding in every way. Significant infrastructures, such as hotels, educational institutions, and large residential complexes are being built. Historically, two major earthquakes with magnitudes of 6.5 Mw struck the island in 1953 and 1996. Potential liquefaction areas have been detected on the island's east coast as a result of these significant earthquakes. In this case study, the liquefaction potential of Tuzla and Long Beach in the northern part of Cyprus is estimated using the standard penetration test (SPT) data from more than 200 boreholes at different locations at the sites. The overall results are presented in a liquefaction risk index obtained from the factor of safety (FS) coefficient. It is clear that both study areas are susceptible to liquefaction. Thus, risk index maps are prepared to identify susceptible liquefiable areas. In addition, the average factor of the safety line was introduced for both sites to create a correlation between the liquefaction risk area and FS values of every borehole. It is clear that the adopted approach precisely provides the suspected depth of the liquefiable soil layer when compared with the risk index maps. Additionally, the results prove that the liquefaction potential must be considered during the design stage of new infrastructure in these areas.

Keywords: liquefaction, hazard mapping, standard penetration testing, factor safety coefficient

\section{Introduction}

Soil liquefaction is a significant design issue for a wide range of structures. Liquefaction causes ground failures that consist of bearing capacity loss, lateral spreading, and flow, resulting in massive settlement of structures. During an earthquake, the pore pressure increases due to the position change of the saturated soil particles. Subsequently, the soil begins to act like a liquid, which is defined as liquefaction. The Cyprus Arc, which caused the earthquakes in Cyprus, forms a tectonic boundary between the 
African and Eurasian lithospheric plates in the region where Cyprus is located (Hall et al., 2005). More than 400 earthquakes occurred in certain parts of the island and in the surrounding countries between 1896 and 2004, including fourteen that caused damage and injuries.

Seed and Idriss (1967) reported that the most known liquefaction occurred during the Niigata earthquake in Japan, which had a magnitude of 7.5 Mw. This liquefaction has attracted the attention of researchers in the field of soil liquefaction. A well-known example of soil liquefaction close to Cyprus occurred in Adapazar1, Turkey, on August 17, 1999, also called the Kocaeli earthquake (Erdik, 2001). This devastating earthquake had a magnitude of $7.4 \mathrm{Mw}$ and occurred at a focal distance of $11 \mathrm{~km}$ from the city. This resulted in the fatality of thousands of people and destroyed a large part of the city. Soil liquefaction was observed after this earthquake. Bray and Sancio (2006) reported that fine-grained soils (clay and silt) were liquefied at 12 building sites in the Adapazar1 region as a result of the Kocaeli earthquake. One of the latest case studies conducted by Kayabaşı and Gokceoglu (2018) considered the related steps for determining the liquefaction potential of a site using a standard penetration test (SPT). The authors carried out a case study for a $6.94 \mathrm{Mw}$ earthquake from an approximately $40 \mathrm{~km}$ long fault line that could cause liquefaction in Eskişehir, Turkey. The authors further analyzed liquefiable soil layers using SPT, determining their factor of safety results with the data from ten boreholes. However, they did not average the blow counts, as was done in this study. Only the average safety factor for the site can provide valid liquefiable soil depth information. Another case study was conducted by Wadi et al. (2021), which followed similar steps by investigating the data from 28 boreholes with SPT measurements. The authors reported that saturated subsurface clay and silt soil up to a depth of $4 \mathrm{~m}$ had a low factor of safety (FS) value, which caused liquefaction risk for a designed 7.5 $\mathrm{Mw}$ earthquake located in Nigeria's Upper Benue region. After a depth of $4.5 \mathrm{~m}$, the liquefaction risk disappeared because of the occurrence of very dense and stiff clay sands. Abdullah and Aal (2021) investigated safety factors and potential liquefaction by measuring 214 SPT boreholes and utilizing a geographical information system application. As a result, they produced a potential liquefaction index and risk index hazard map for Jeddah City in the Kingdom of Saudi Arabia. Their results did not provide each FS value for the investigated boreholes, as the purpose of this case study was to obtain the most precise hazard map.

The purpose of this study is to develop an improved and precise liquefaction risk index for the evaluation and translation of the outcomes into maps to establish susceptible liquefiable areas. The SPT data from more than 200 boreholes were evaluated. The results indicate that the liquefaction risk of the Tuzla and Longbeach areas under a designed $6.5 \mathrm{Mw}$ earthquake simulation were high, resulting in severe liquefaction of the soil. The results were further discussed with respect to similar studies, and the validity of the proposed hazard maps was evaluated in light of other studies. 


\section{Methods of Evaluation}

The evaluation and analysis of the liquefaction potential of soil sediments involve the characterization of the soil subjected to seismic loading and the characterization of soil resistance to liquefaction. Two possible methods can be compared to determine the liquefaction potential of soil. The first approach is plotting the magnitude versus epicentral distance to the farthest occurrence of the liquefaction, which presumes a simple relation and generalizes the liquefaction occurrence (Kuribayashi and Tatsuoka 1975). Other parameters, such as the zone of faulting, the total energy released, and soil characteristics are even more critical than the magnitude and epicentral distance. However, the magnitude plots versus the epicentral distance provide a valid approximation. The second approach was developed by Seed and Idriss (1971), which estimates a shear stress level that can be generated at the site under a given designed earthquake. The liquefiable soil zone can be determined by comparing the induced shear level and liquefaction resistance.

The prediction of liquefaction resistance developed by Seed and Idris (1971) is used worldwide and is also called the "Simplified Procedure". The procedure was initially developed for the SPT and has been revised several times. In addition to the SPT, two additional procedures were developed and are being used for liquefaction resistance. These are the cone penetration test (CPT) and shear wave velocity test. According to Youd and Idriss (2001), the SPT and CPT are the most commonly used methods, and numerous studies have been performed utilizing these tests. Each test method has advantages and disadvantages, as shown in Table 1. In this study, SPT data were utilized as it is the most widely available site investigation method and numerous data were available for the subject sites.

The liquefaction resistance was specified as an FS coefficient for each soil stratum, and probabilistic equations were developed from this coefficient. One of the earliest probabilistic equations was developed by Iwasaki (1984), which provided a risk index against liquefaction up to a depth of $20 \mathrm{~m}$. The author reported that there could be no liquefaction risk occurring in the soil strata below $20 \mathrm{~m}$. In the current case study, Seed's (1971) liquefaction resistance and Iwasaki's (1984) risk index were used to determine each layer's liquefaction risk and produce liquefaction index maps.

\subsection{Susceptible Soil Classification}

Seed et al. (2003) reported that liquefaction susceptibility criteria were applied to soil strata up to $20 \mathrm{~m}$ deep for the boreholes. The soil was classified as liquefiable when the liquid limit was less than 37\% and the plasticity index (PI) was less than 12\%. The recommendations of Seed et al. (2003) and Bray et al. (2004) for fine-grained soils for the 12 construction sites in the 1999 Adapazar Kocaeli earthquake are shown in Fig. 1. As described by Seed, even soils consisting of soil layers with a PI higher than 12\% were liquefied in that region. 


\subsection{Cyclic Shear Stress Ratio}

The shear stress created on the soil strata was computed using the original simplified technique published by Seed and Idriss (1971) and Seed et al. (1975), which considered the soil strata as a rigid body stimulated by seismic loading at the base. The cyclic shear stress ratio (CSR) can be expressed as:

$$
C S R=0.65 \times\left(a_{\max }\right) \times\left(\sigma_{v} / \sigma_{v}^{\prime}\right) \times r_{d}
$$

where $\sigma_{v}$ represents the total vertical stress and $\sigma^{\prime}{ }_{v}$ represents effective vertical stress, which is the maximum ground acceleration parameter. $a_{\max }$ was calculated using a formula developed by Fukushima and Tanaka (1990) and the result was compared with a study by Algermissen and Rogers (2004) that was performed earlier for the same territory. It can be expressed as:

$$
\log _{10} a_{\max }(\mathrm{gal})=0.41 M s \log _{10}\left(R+0.032 \times 10^{0.41 M s}\right)-0.0034 R+1.3
$$

where $1 \mathrm{gal}=1.02 \times 10^{\wedge}(-3) \mathrm{g}, R$ is equal to $20 \mathrm{~km}$, and $M s$ represents a 6.5 magnitude earthquake. The calculated $\mathrm{a}_{\max }$ results of a $6.5 \mathrm{Mw}$ designed earthquake for the Algermissen \& Rogers study and this study (using Eq. 2) were very similar for Tuzla and the same for Long Beach. For the Tuzla area, a maximum ground acceleration of 0.23 was calculated in terms of gravitational acceleration $(\mathrm{g})$. Similarly, 0.22 was calculated in the Algermissen and Rogers (2004) study for the same territory, as shown in Fig. 2.

In reality, soil is more similar to a flexible body than a rigid one. As a result, the rigid body shear stress decreases by a correction factor or stress reduction factor $\left(\mathrm{r}_{\mathrm{d}}\right)$ to yield the deformable body shear stress, which measures the attenuation of peak shear stress with depth due to nonelastic soil behaviour. In this study, the $r_{d}$ factor was determined using the influence of the Liao and Whitman (1986) $r_{d}$ equations, expressed as:

$$
\begin{aligned}
& r_{d}=1-0.00765 \times z \text { for } z<9.15 m \\
& r_{d}=1.174 \times z \text { for } 9.15 m<z<23 m
\end{aligned}
$$

\subsection{Cyclic Resistance Ratio}

Different liquefaction evaluation procedures were developed using the SPT, which began in 1964 with the Niigata earthquake. After the earthquake, many researchers published numerous developments on liquefaction. Case studies that observed and analyzed liquefaction cases have become very important for the investigation of liquefiable soils. The procedures generated to obtain the safety factor from the 
134 SPT test blow numbers that were determined by Seed and Idriss (1971) and Seed et al. (1983) have

135 become the standard procedures for liquefaction susceptibility studies.

136 In this case study, a simplified ratio based on Seed and Idris' (1971) procedure is proposed to obtain the

137 FS against liquefaction at soil strata depths of 1 to $20 \mathrm{~m}$.

138 The cyclic resistance ratio (CRR) was calculated from a study by Youd and Idriss (2001) and is used to

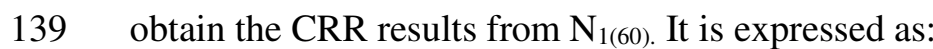

$$
C R R=\frac{1}{34-N_{1(60)}}+\frac{N_{1(60)}}{135}+\frac{50}{\left[10 \times N_{1(60)}+45\right]^{2}}-\frac{1}{200}
$$

The calculation of $N_{1(60)}$ (corrected SPT blow numbers) originated in the SPT test for $30 \mathrm{~cm}$ penetration blow counts and was developed by Skempton (1986). It corresponds to the normalized value using various in situ test corrections at a geostatic pressure of 1 bar applied to the overburden coefficient. It is expressed as:

$$
N_{1(60)}=N \mathrm{spt} \times C_{E} \times C_{N} \times C_{R} \times C_{B} \times C_{S}
$$

where $C_{N}$ is the overburden correction factor, $C_{E}$ is the energy correction factor, $C_{R}$ is the rod length correction factor, $C_{B}$ is the borehole diameter correction factor, and $C_{S}$ is the liner correction factor.

The $\mathrm{C}_{\mathrm{N}}$ correction factor is calculated using a formula developed by Liao and Whitman (1986), which is expressed as:

$$
C_{N}=\left(P a / \sigma_{v_{0}}^{\prime}\right)^{2}
$$

According to Liao and Whitman (1986), the proposed $C_{N}$ correction factor must be between 0.5 and 2.0. The $C_{N}$ correction can only be applied to calculate the relative density and shear resistance angle and cannot be implemented on undrained parameters.

According to Youd and Idriss (2001), it is necessary to apply a fineness correction to the equivalent $\mathrm{N}_{1(60)}$ to obtain the clean sand equivalent $\mathrm{N}_{1(60) \text { cs }}$ from which to extrapolate the SPT blow number of the sand. Numerous equations have been proposed in the literature for clean sand correction. The most widely used calculation to correct the $\mathrm{N}_{1(60)}$ blow number to $\mathrm{N}_{1(60) \text { cs }}$ was proposed by Youd and Idriss (2001) and is expressed as:

$$
N_{1(60) c s}=N_{1(60)}+\Delta N_{1(60)}
$$
used for clean sand correction (Idriss and Boulanger 2008; Seed et al. 1985; Cetin and Seed 2004; Cetin et al. 2018) are shown in Fig. 3. 
The corrections and evaluations data provided by the investigations of Idriss and Boulanger (2010) were taken into consideration to formulate the equation used in this case study. The equation was also developed by averaging all notably essential literature studies, as shown in Fig. 3. The proposed equation for clean sand correction is expressed as:

$$
\begin{gathered}
F C \leq \% 5 N_{1(60) C S}=N_{1(60)} \\
\% 5 \leq F C \leq \% 35 N_{1(60) C S}=N_{1(60)}+5.6(F C-5) / 30 \\
F C>\% 35 N_{1(60) C S}=N_{1(60)}+5.6
\end{gathered}
$$

The magnitude scale factor (MSF) can be applied to the CSR formula as a division factor or CRR as a multiplication factor. For a 7.5 magnitude earthquake, the MSF is taken for granted as the one in the literature. The scale factor needs to be converted to a 7.5 magnitude scale for earthquakes of different magnitudes. Youd et al. (1997) developed an MSF conversion formula that considered the convenience of calculating a particular earthquake factor, which is expressed as:

$$
M S F=\left(\frac{M_{W}}{7.5}\right)^{n}
$$

where $M_{w}$ stands for the earthquake moment magnitude and $n$ is the exponent. It was recommended by Idriss (1997) that the lower bound be set to $n=-2.56$. Furthermore, it was recommended by Andrus and Stokoe (1997) that the upper limit be set to $n=-3.3$.

Deposits are subjected to an overburden pressure in liquefiable soils. Therefore, the calculated CRR

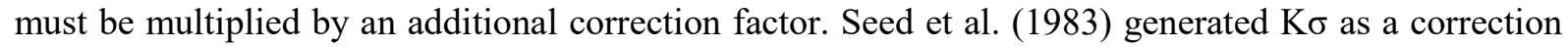
factor that extrapolated the simplified method. The correction factor must be applied to soil layers above $100 \mathrm{kPa}(1 \mathrm{~atm})$ pressure due to the nonlinearity between the CRR and effective overburden pressure. Different approaches are presented in the literature and different modifications were performed to improve the liquefaction analysis.

\subsection{Liquefaction Potential Index}

The prediction of the liquefaction potential index of the boreholes was calculated using a formula provided by Iwasaki et al. (1984), expressed as:

$$
L P I=\int_{0}^{20} F(z) W(z) d z
$$

where $F(z)$ is a function of the FS against liquefaction, and $F(z)=1$-FS when FS $<1$. $z$ is the depth below the surface in meters, computed from $W(z)=10-0.5 z$ up to a depth of $20 \mathrm{~m}$. According to the 
proposed method, the risk of liquefaction of the soil layer is valid up to a depth of $20 \mathrm{~m}$. There are many debates in the literature that the soil can be liquefied until FS $=1.2$. Sonmez (2003) was inspired by the Iwasaki (1984) formulation, which stated that soils could be liquefied up to the range of $1<\mathrm{FS}<1.2$. Subsequently, the author proposed the following:

$$
F(z)=2 \times 10^{6} e^{-18.427 F S}
$$

The equation becomes $F(z)=0$ if FS is more significant than 1.2 because no liquefaction occurs after that number.

\section{Results and Discussion}

\subsection{Borehole Locations}

The borehole data that were transferred into maps were provided by the Union of the Chambers of Cyprus Turkish Engineers and Architects, Chamber of Civil Engineers, and a soil layer database. Both sites were located in a newly developing area and had a coast on the Mediterranean Sea, as shown in Figs. 4 and 5. The SPT borehole locations and streams are also shown in Figs. 4 and 5.

In both locations, the river streams that carry rainfall from large basins reach the Mediterranean Sea from these areas. It should be noted that the stream that carries the rainfall to the Tuzla area has a much greater basin than Long Beach. Therefore, it was suspected that the Tuzla area had a much more significant potential to contain alluvial soils that can cause liquefaction.

\subsection{Investigation of Boreholes}

The primary data from the on-site SPT boreholes provided an initial idea of the liquefaction potential of the sites. Notably, lower blow counts for a penetration depth of $30 \mathrm{~cm}$ may prevent liquefaction, but the safety value factors of the boreholes must also be considered to calculate the liquefaction risk. The riskiest SPT borehole blow counts from the Longbeach and Tuzla sites are shown in Figs. 6 and 7.

The $\mathrm{N}_{1.60}$ (corrected blow count) values are generally shown to be between 5 and 10. From these low blow count results, it is suspected that the named sites have the potential for liquefaction risk. If the soil characteristics are appropriate for liquefaction, low FS values are expected in these borehole locations. In some instances, investigation of numerous boreholes was needed for close locations because human mistakes could have occurred while performing the site investigations or if the specific area had varying soil characteristics over short distances.

\subsection{Factor of Safety Distributions}

A liquefaction evaluation was performed for Longbeach and Tuzla to obtain a preliminary result. Data were collected from more than 200 boreholes that were separated by approximately $8 \mathrm{~km}$ along 
streamlines located near the sites, as shown in Figs. 4 and 5. The FS values were calculated to determine the risk of all the boreholes located at the site. The number of corrected blow counts for the $30 \mathrm{~cm}$ depth $\left(\mathrm{N}_{1.60}\right)$ was considered through a $20 \mathrm{~m}$ depth. $\mathrm{N}_{1.60}$ values were not considered for some locations because there was no liquefaction risk due to the presence of clays with a high plasticity index or very dense sands with high blow counts. FS values were transferred to graphs to clarify the dimensional distribution of FS values for each depth of all boreholes, as shown in Figs. 8 and 9. The FS values of the boreholes above 1.2 for the Tuzla area, indicating that the risk of liquefaction was low, as shown in Fig. 8 . Therefore, this is considered to be a safe region against liquefaction. The safe region boundary that has a 1.2 FS value is shown as a bold black line in Figs. 8 and 9. According to the Buiding Seismic Safety Council (BSSC, 2009), the FS value between 1.1 and 1.3 is considered appropriate for building sites because liquefaction may occur if FS exceeds 1. In this study, FS>1.2 was used considering the risk of occurrence of liquefaction and in accordance with the recommendation by BSSC. Furthermore, the case studies that used FS $>1$ and predicted safe regions did not consider the cost of liquefaction related damages such as property destruction and rehabilitation costs.

The Long Beach area is expected to be less risky because its FS values are close to the safe region. The crucial point of these graphs is to show the critical depths that are more likely to be liquefiable. The blue lines in Figs. 8 and 9 represent the average FS values for each area. It is also characteristic at both locations that the liquefaction suspicion is greater at the surface and reduces for deeper strata. FS values are frequently below 1.2 for a depth up to $8 \mathrm{~m}$ in the Tuzla area, indicating that the expectation of liquefaction is relatively high up to that depth. This information can also be observed in the average FS distribution line. The average FS distribution lean-to increased after a depth of $8 \mathrm{~m}$ in the Tuzla area, so the liquefaction possibility is expected to decrease. However, the evaluated Long Beach area appears less likely to be liquefiable if an earthquake of magnitude 6.5 hits Cyprus. One likely factor is the average FS values being close to 1 in depths of $4 \mathrm{~m}$ and above, as shown in Fig. 9. Furthermore, the river basin in Longbeach has a lesser area than that in Tuzla, which leads to the assumption that the rivers carry a minuscule amount of alluvial soil to the selected area. The risk index is expected to indicate that the Long Beach area is less risky with less likelihood of being liquefiable than Tuzla.

\subsection{Factor of Safety Contour Maps}

The FS values of each site at depths of 3 and $6 \mathrm{~m}$ are shown as contour maps in Figs. 10 and 11. Both sites were determined to be riskier at shallow depth levels, so liquefaction risk was checked at 3 and 6 $\mathrm{m}$. The black areas in the map represent the territories at risk of liquefaction. The areas that were determined as risky in Tuzla were widely separated at depths of 3 and $6 \mathrm{~m}$, as shown in Fig. 10. The FS values for the Longbeach area were relatively higher, so the risk areas were not widespread for the depths of 3 and $6 \mathrm{~m}$, as shown in Fig. 11. However, there were some specific areas near the coast that demonstrated a high possibility of liquefaction. 


\subsection{Risk Index Maps}

The risk index maps in Figs. 12 and 13 were obtained from the Iwasaki (1984) liquefaction index. According to Iwasaki (1984), liquefaction can occur up to a depth of $20 \mathrm{~m}$. However, the possibility of liquefaction is not the same at different depths. The occurrence of liquefaction is higher at shallow depths because water can reach the surface much more quickly when the pore water pressure increases as a result of an earthquake and if the liquefiable soil is close to the surface level. As a result, the probability of liquefaction occurrence is higher. From this perspective, the method used to calculate the liquefaction index must be multiplied by a factor. This study proposes a factor of 1 for the surface level. Additionally, the factor is 0 after a depth of $20 \mathrm{~m}$ because liquefaction is not expected here. As suggested in this study, the liquefaction depth factor can be assumed to decrease linearly from the surface to the deepest level. The liquefaction risk was calculated using the liquefaction index of Iwasaki (1984) multiplied by a factor of depth, and the liquefaction risk of the soil strata was calculated accordingly from the summation of different depths.

The green areas in Figs. 12 and 13 represent the areas with a low possibility of liquefaction for a designed 6.5 magnitude earthquake. The yellow areas represent the average-risk group, and the orange and red zones represent the high and very high-risk areas. The risk index map in Fig. 12 indicates that the Tuzla site was widely within the average-risk group for liquefaction. Low FS results were calculated at shallow depths due to numerous streamlines that pass through the Tuzla area and carry rainfall from a larger area of the basin. Therefore, a risk of liquefaction was already expected for this region. Wotherspoon et al. (2012) prepared a case study investigating a very similar territory as the Tuzla region, with river streams passing $3 \mathrm{~km}$ through the city. The authors mentioned that during a 7.1 $\mathrm{Mw}$ earthquake, severe liquefaction was observed in that area. The water table was $2 \mathrm{~m}$ below the ground level, which was very close to the Tuzla region, and liquefaction was observed in shallow depths. This study shows that liquefaction occurred in shallow depths, which is parallel to Worherspoon's case study. This indicates that the occurrence of liquefaction also depends on the river streams and their basin areas. However, the Long Beach area appears less risky than the Tuzla region, as shown in Fig. 13. Again, some specific regions of this area contain average and high risk, but they are not too extensive. There are three reasons for this: the soil in Long Beach is denser than Tuzla, fewer streamlines pass through the region to carry rainfall from a relatively minor basin, and the Long Beach region is relatively far from the Cyprus arc, so the maximum ground acceleration has a more negligible effect against designed earthquakes.

Although there is no recent sismic activity that has caused liquefaction phenomena on the island of Cyprus, historical records show that most parts of the island are vulnerable to liquefaction risk. Michaelides (1988) studied the construction, foundation conditions, and final abandonment of the port of Amathus (Figure 2), which is located on the south coast of Cyprus, $90 \mathrm{~km}$ from the investigation area. 
Author stated that the moles of the port was founded on a weak, compressible sandy layer of marine deposits which is characterized as highly liquefaible when prown to earthuakes. Authors further stated that likely reason for the abandonment of the port could be a gradual and regional tectonic lowering of the sea bottom of the Limassol Bay and/or experience settlement due to the weak foundation stratum in the vicinity of the port possibly accompanied by liquefaction phenomena during a strong seismic event between the 6th and 7th centuries AD. In another study, Antonopoulos (1980) investigated the seismic sea-wave events in the eastern Mediterranean from the birth of the Christ to $500 \mathrm{AD}$. The authors reported that the city of Salamis (Figure 2), $3 \mathrm{~km}$ from Tuzla, $7 \mathrm{~km}$ from the Long Beach area and located at the mouth of the Pedieos rivers, which is one of the rivers that transports alluvial soil to the Tuzla region, was hit by a strong earthquake in $342 \mathrm{AD}$. The authors further reported that as a result of this earthquake part of the ancient city of Salamis collapsed and sank into the Mediterean. Therefore, it is clear from the historical records that the investigation areas have been subjected to liquefaction phenomena.

\subsection{Comparison with Previous Studies}

Biryllmaz (2009) and Cetin (2009) conducted two different case studies to investigate the Tuzla area against liquefaction under the same earthquake conditions. Biryılmaz (2009) investigated the Tuzla region using 38 SPT borehole data. The author utilized the simplified procedure of Seed and Idriss (1971) with Iwasaki's liquefaction potential index method (1984), and prepared the liquefaction risk index map with respect to surface geology aspects. In addition, Cetin (2009) used 18 CPT data to conduct a risk index map by considering the liquefaction risk index method apart from Iwasaki (1984). Cetin (2009) risk index method was converted to Iwasaki's format (1984) to enable an appropriate comparison. For both studies, the closest SPT borehole and CPT locations were compared to the SPT borehole locations of this study to achieve the most accurate comparison. Figure 14 presents the comparison of all borehole locations, shown in Fig. 4, regarding the liquefaction risk of Biryllmaz (2009) and Cetin (2009) studies. The results show that there is a significant similarity between all case studies conducted for the Tuzla area. Moreover, Table 2 depicts that there is an $82 \%$ correlation ratio between Cetin's liquefaction hazard map (2009) and the map developed in this study. The high correlation between this study and Cetin (2009) studies is due to the precision of CPT measurements against liquefaction, the high correlation shows that these studies support each other with regard to liquefaction occurring under the same earthquake scenarios. The slight variance in the two studies might be due to differences in the number of data points that can affect the sensitivity of hazard maps against liquefaction. Additionally, it can be seen in Table 2 that the correlation between this study and Biryllmaz (2009) reduced to $70 \%$ for the same designed earthquake scenario condition. Eventhough Biryılmaz (2009) used a similar approach to this study, generalizing the liquefaction risk in respect to surface geology aspects resulted in a reduction in the correlation index. Such hypothesis proves valid if one compares the correlation between Biryllmaz (2009) and Cetin (2009) that returns an even lower correlation index of 60\%. 
Therefore, it can be concluded that the approach adopted in this study to calculate the liquefaction risk and form the hazard map is valid and can be extended to other regions with similar geological, topographical, and geotechnical aspects.

\section{Conclusions}

This study proposed an improved and precise liquefaction risk index for the evaluation and translation of outcomes into maps to establish susceptible liquefiable areas. The liquefaction potential of Tuzla and Long Beach in the northern part of Cyprus Island was estimated using the SPT data from more than 200 boreholes. The overall results were presented in a liquefaction risk index and clearly indicated that both study areas were susceptible to liquefaction. Risk index maps were prepared, and the average factor of the safety line was introduced to create a correlation between the liquefaction risk area and FS values of every borehole. Based on the theoretical and experimental results obtained in this study, the following conclusions can be drawn:

- The results showed that most of the FS values were under 1.2 for the Tuzla area. However, the risk of liquefaction was high down to a depth of $8 \mathrm{~m}$ in the soil strata. A contour map was developed using FS values for the Tuzla area to evaluate liquefaction for the proposed depths.

- The results for Long Beach appeared more promising than Tuzla but were still suspicious. There was a risk of liquefaction up to a depth of $6 \mathrm{~m}$ in specific areas, and the contour maps showed that the FS values were relatively higher and indicated less risk against liquefaction occurrence.

- The maximum ground acceleration was calculated for a designed earthquake, and the results were in accordance with a previous study conducted in the same region.

- Numerous studies on clean sand correction approaches were evaluated, and various case studies were considered to create the most suitable equation for clean sand correction.

- The average factor of the safety line was created to demonstrate the risk index occurrence against liquefaction at different depths up to $20 \mathrm{~m}$.

- A liquefaction depth factor was suggested as an extension of the Iwasaki (1984) risk index formula to obtain a more precise forecast.

It is clear that the adopted approach precisely provided the suspected depth of the liquefiable soil layer when compared with the risk index maps. Additionally, sustainable ground improvement methods and foundations should be considered in accordance with the results for both sites. Finally, the results prove that the liquefaction potential must be considered during the design stage of new infrastructure in these areas.

\section{Statements and Declarations}


Funding / Competing Interests: The authors express their appreciation to the Office of Research Coordination and Support, Middle East Technical University, Northern Cyprus Campus, for funding this research group. Scientific Research Project Code FEN-20-YG-4.

\section{References}

Abdullah GMS, el Aal AA (2021) Liquefaction hazards mapping along Red Sea coast, Jeddah city, Kingdom of Saudi Arabia. Soil Dyn Earthquake Eng 144. https://doi.org/10.1016/j.soildyn.2021.106682

Algermissen T, Rogers A (2004) A Cyprus earthquake hazard assessment: maps of probabilistic peak ground acceleration and uniform-hazard pseudo-absolute acceleration spectral response. UNOPS Seismic Hazard and Risk Assessment of the Greater Nicosia Area Report

Andrus R, Stokoe K (1997) Liquefaction resistance based on shear wave velocity

Antonopoulos J, (1980) Data from investigation on seismic sea-waves events in the Eastern Mediterranean from the birth of Christ to 500 AD. Annals of Geophysics, 33. https://doi.org/10.4401/ag-4701

Biryilmaz E (2009) The engineering geology of Tuzla region of Famagusta Cyprus. Dokuz Eylül Üniversitesi. Retrieved from https://tez.yok.gov.tr/UlusalTezMerkezi/TezGoster?key=CwVIqqBuz1VkysVpueogAcy1YwhxX4 dQiVnoOY9j-dh2PqL1fEIfZjZWCJXSOJ7w

Bolton Seed H, Tokimatsu K, Harder LF, Chung RM (1985) Influence of SPT procedures in soil liquefaction resistance evaluations. J Geotech Eng 111. https://doi.org/10.1061/(ASCE)07339410(1985)111:12(1425):1425-1445

Boulanger RW, Idriss IM (2006a) Liquefaction susceptibility criteria for silts and clays. J Geotech Geoenviron Eng 132. https://doi.org/10.1061/(asce)1090-0241(2006)132:11(1413):1413-1426

Boulanger RW, Idriss IM (2008) Closure to "liquefaction susceptibility criteria for silts and clays" by Ross W. Boulanger and I.M. Idriss. J Geotech Geoenviron Eng 134. https://doi.org/10.1061/(asce)1090-0241(2008)134:7(1027):1027-1028

Bray JD, Sancio RB (2006) Assessment of the liquefaction susceptibility of fine-grained soils. J Geotech Geoenviron Eng 132. https://doi.org/10.1061/(asce)1090-0241(2006)132:9(1165):11651177 
Building Seismic Safety Council (2009) NEHRP Recommended Seismic Provisions for New Buildings and Other Structures, FEMA P-1050. Fema P-750 II: Retrieved from https://www.wbdg.org/FFC/DHS/ARCHIVES/femap750_2009.pdf

Cetin KO, Seed RB, DER Kiureghian A, et al (2004) Standard penetration test-based probabilistic and deterministic assessment of seismic soil liquefaction potential. J Geotech Geoenviron Eng 130. https://doi.org/10.1061/(asce)1090-0241(2004)130:12(1314)

Cetin KO, Seed RB, Kayen RE, et al (2018) SPT-based probabilistic and deterministic assessment of seismic soil liquefaction triggering hazard. Soil Dyn Earthquake Eng 115. https://doi.org/10.1016/j.soildyn.2018.09.012:698-709

Cetin KO (2009) TRNC Gazimagusa Tuzla region seismic seismic soil liquefaction assessment report. Union of the Chambers of Cyprus Turkish Engineers and Architects, Chamber of Civil Engineers

Chrysostomou C, Algermissen T, Rogers A, Demetriou T (2004) Seismic risk assessment of Nicosia, Cyprus. 13th WCEE

Fukushima Y, Tanaka T (1990) A new attenuation relation for peak horizontal acceleration of strong earthquake ground motion in Japan. Bulletin of the seismological Society of America 80. https://doi.org/10.1785/BSSA0800040757

Erdik M (2001) Report on 1999 Kocaeli and Düzce (Turkey) earthquakes

Hall J, Calon TJ, Aksu AE, Meade SR (2005) Structural evolution of the Latakia Ridge and Cyprus Basin at the front of the Cyprus Arc, eastern Mediterranean Sea. Mar Geol 221. https://doi.org/10.1016/j.margeo.2005.03.007:261-297

Idriss IM, Boulanger RW (2010) Spt-based liquification triggering procedures. Report UCD/CGM$10 / 02$

Iwasaki T, Arakawa T, Tokida KI (1984) Simplified procedures for assessing soil liquefaction during earthquakes. Int J Soil Dyn Earthquake Eng 3. https://doi.org/10.1016/0261-7277(84)90027-5:49_ 58

Union of the Chambers of Cyprus Turkish Engineers and Architects, Chamber of Civil Engineers, soil layer database. https://www.ktimo.org/Zemin (visit date 2110 2020)

Kuribayashi E, Tatsuoka F (1975) Brief review of liquefaction during earthquakes in Japan. Soils Found 15. https://doi.org/10.3208/sandf1972.15.4_81:81-92 
Liao SSC, v Whitman RV (1986) Overburden correction factors for SPT in sand. J Geotech Eng 112. https://doi.org/10.1061/(ASCE)0733-9410(1986)112:3(373):373-377

Michaelides P, (1988) The ancient port of Amathus (Cyprus): its construction, foundation conditions and final abandonment. In The Engineering geology of ancient works, monuments and historical sites: preservation and protection, proceedings of an international symposium organized by the Greek National Group of IAEG, Athens, 19-23 September 1988 (Vol. 3, pp. 1597-1604).

Pekcan O, Çetin K, Bakır B (2004) Cyclic behavior of Adapazarı silt and clay mixtures. https://doi.org/10.1061/jsfeaq.0000981. J Soil Mech Found Div 93. 11th International Conference on Soil Dynamics and Earthquake Engineering

Seed HB, Idriss IM (1967) Analysis of Soil Liquefaction: Niigata Earthquake

Seed HB, Idriss IM (1971) Simplified procedure for evaluating soil liquefaction potential. https://doi.org/10.1061/jsfeaq.0001662 ASCE J Soil Mech Found Div. 97

Seed HB, Idriss IM, Arango I (1983) Evaluation of liquefaction potential using field performance data. J Geotech Eng 109. https://doi.org/10.1061/(ASCE)0733-9410(1983)109:3(458):458-482

Seed HB, Idriss IM, Lee KL, Makdisi FI (1975) Dynamic analysis of the slide in the lower San Fernando dam during the earthquake of February 9 1971. ASCE J Geotech Eng Div 101. https://doi.org/10.1061/ajgeb6.0000371

Seed RB, Cetin KO, Moss RES, et al (2003) Recent advances in soil liquefaction engineering: A unified and consistent framework. In: Proceedings of the 26th annual ASCE los Angeles geotechnical spring seminar: Long Beach, CA

Skempton AW (1986) Standard penetration test procedures and the effects in sands of overburden pressure, relative density, particle size, ageing and overconsolidation. Géotechnique 36. https://doi.org/10.1680/geot.1986.36.3.425:425-447

Sonmez H (2003) Modification of the liquefaction potential index and liquefaction susceptibility mapping for a liquefaction-prone area (Inegol, Turkey). Environ Geol 44. https://doi.org/10.1007/s00254-003-0831-0:862-871

Wadi D, Wu W, Malik I, et al (2021) Assessment of liquefaction potential of soil based on standard penetration test for the upper Benue region in Nigeria. Environ Earth Sci 80. https://doi.org/10.1007/s12665-021-09565-y 
449 Wotherspoon LM, Pender MJ, Orense RP (2012) Relationship between observed liquefaction at 450 Kaiapoi following the 2010 Darfield earthquake and former channels of the Waimakariri River. Engineering Geology 125: https://doi.org/10.1016/j.enggeo.2011.11.001

452 Youd TL, Idriss IM (1997) Liquefaction criteria based on statistical and probabilistic analyses 453 Proceedings of the NCEER workshop on evaluation of liquefaction resistance of soils, NCEER $454 \quad$ Technical Rep. NCEER-97 22

455 Youd TL, Idriss IM (2001) Liquefaction resistance of soils: Summary report from the 1996 NCEER and 4561998 NCEER/NSF workshops on evaluation of liquefaction resistance of soils. J Geotech

457 Geoenviron Eng 127. https://doi.org/10.1061/(asce)1090-0241(2001)127:4(297):297-313

458

459

460

461

462

463

464

465

466

467

468

469

470

471

472

473

474 


\begin{tabular}{llll}
\hline \hline Feature & SPT & CPT & Vs \\
\hline Past measurements at liquefaction sites & Abundant & Abundant & Limited \\
& & & $\begin{array}{l}\text { Small } \\
\text { strain, no } \\
\text { excess pore } \\
\text { water } \\
\text { pressure }\end{array}$ \\
Type of stress-strain behaviour influencing test & $\begin{array}{l}\text { Large strain, partially } \\
\text { drained }\end{array}$ & $\begin{array}{l}\text { Large strain, } \\
\text { drained }\end{array}$ & Good \\
Quality control and repeatability & Poor to good & Very good & \\
& Good for closely spaced & Very good & Fair \\
Detection of variability of soil deposits & tests & Nongravel & All \\
Soil types in which test is recomended & Nongravel & No & No \\
Soil sample retrieved & Yes & Index & Engineering \\
Test measures index or engineering property & Index & &
\end{tabular}

$4 \overline{\overline{76}}$

477

478

479

480

Table 2 Correlation matrix for comparison of hazard maps of Tuzla

\begin{tabular}{|c|c|c|c|}
\hline & Selcukhan \& Ekinci (n.d) & Cetin (2009) & Biryilmaz (2009) \\
\hline Selcukhan \& Ekinci (n.d) & 1 & 0.82 & 0.70 \\
\hline Cetin (2009) & 0.82 & 1 & 0.60 \\
\hline Biryilmaz (2009) & 0.70 & 0.60 & 1 \\
\hline
\end{tabular}




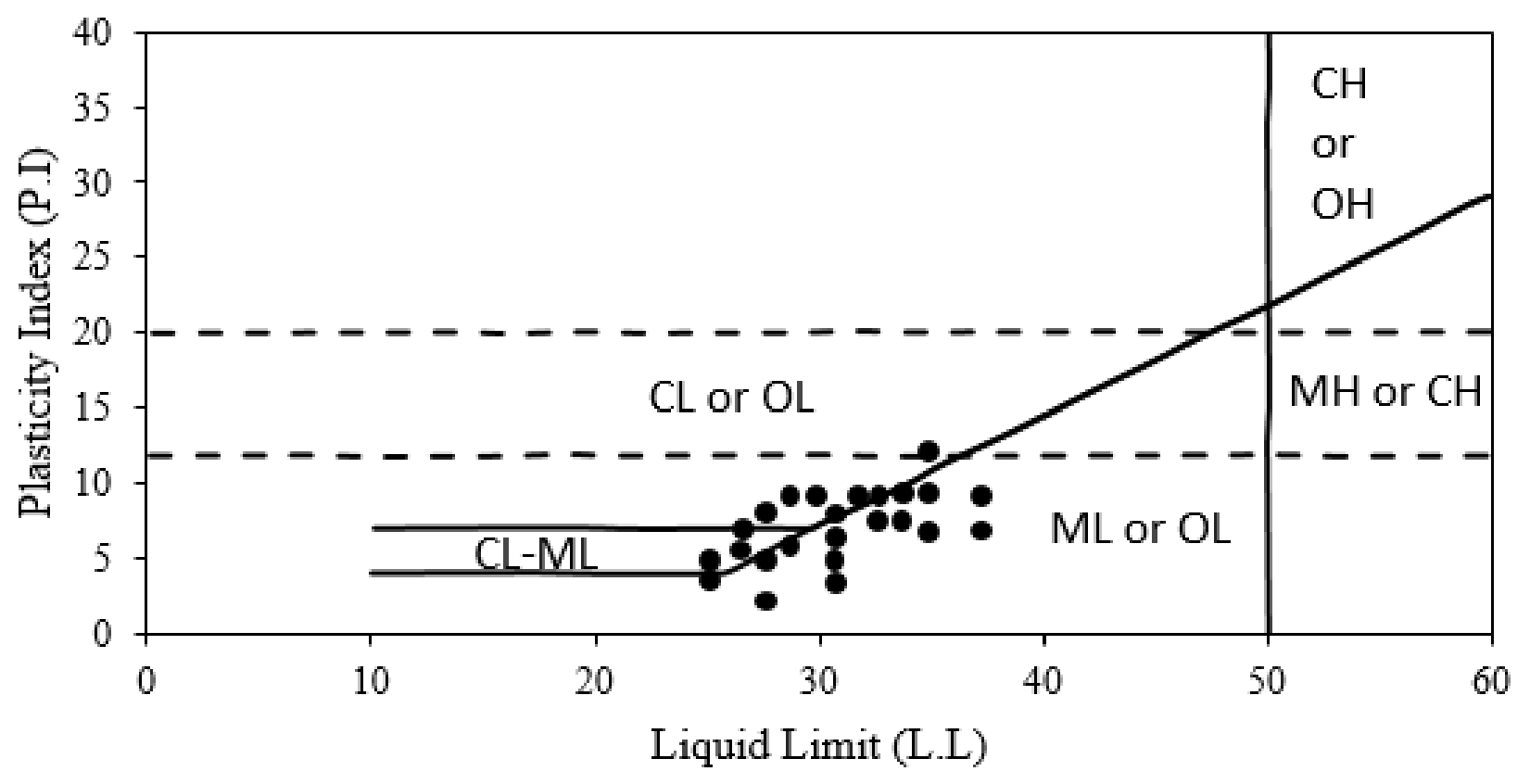

4

Figure 1. 1999 Adapazarl, Kocaeli earthquake liquefied fine-grained region (adapted from Bray et al. (2004)) 


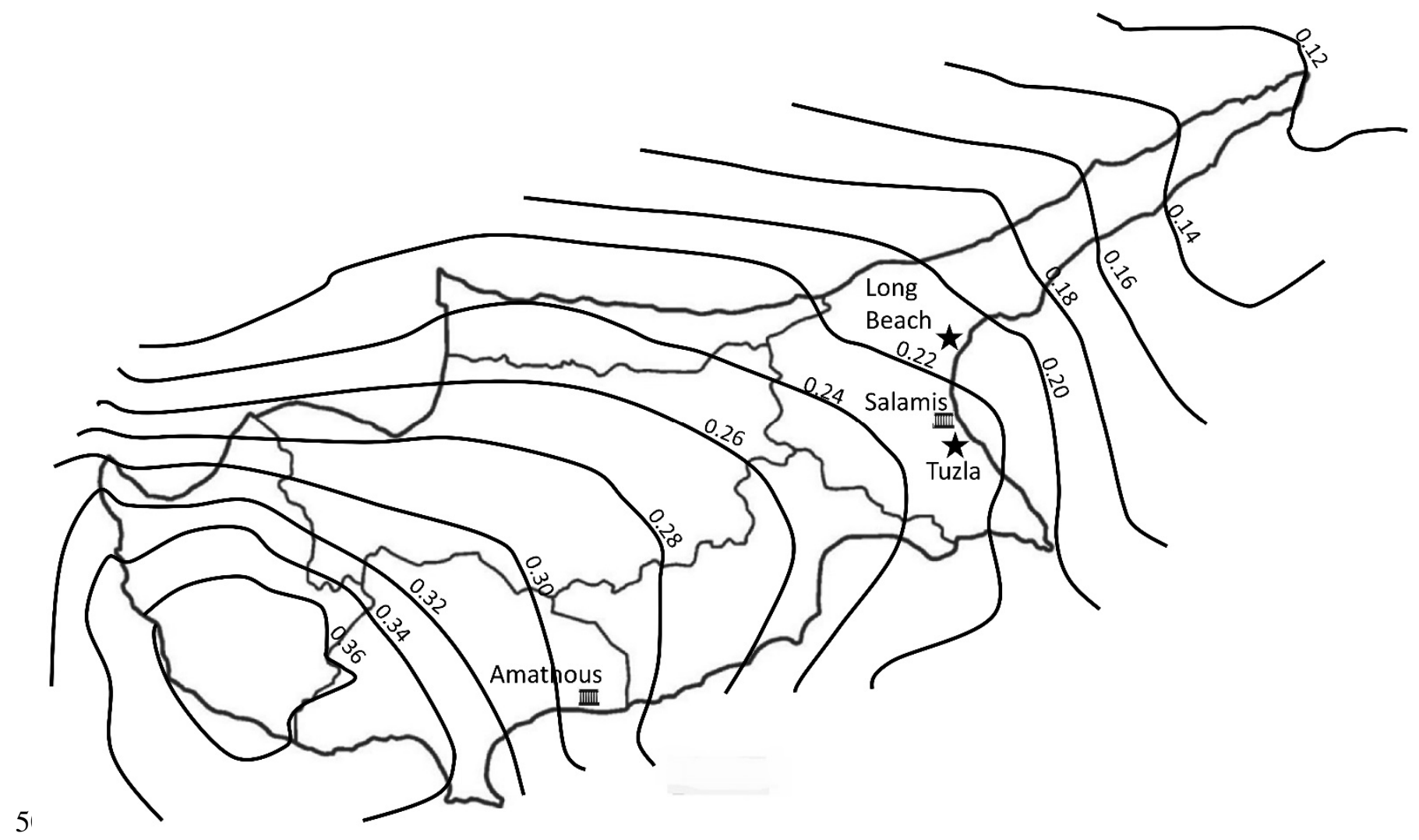

50巴igure 2. Maximum peak ground acceleration values of the Cyprus island for 6.5 Mw designed earthquake and study sites (adapted 503 from Algermissen and Rogers (2004) 

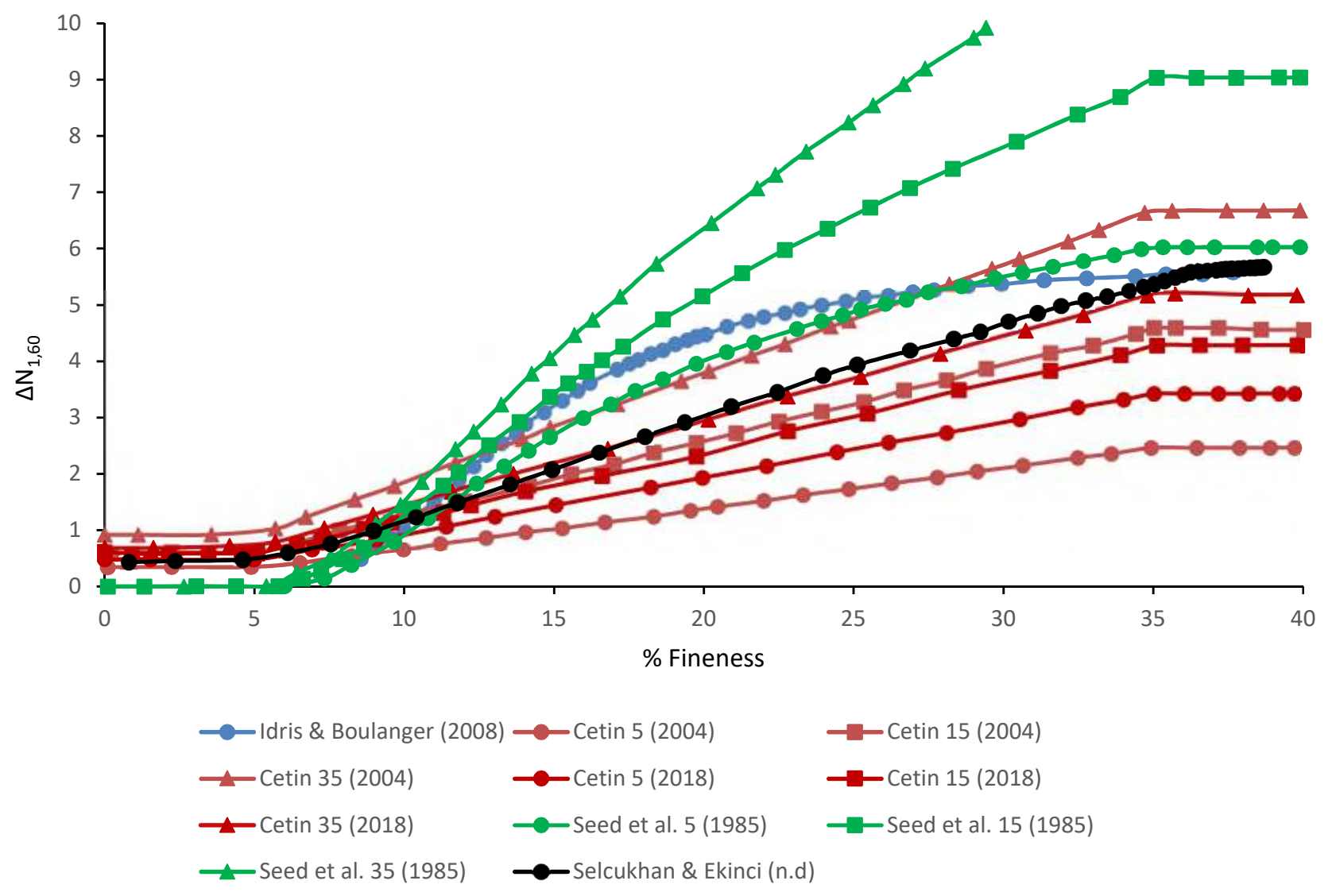


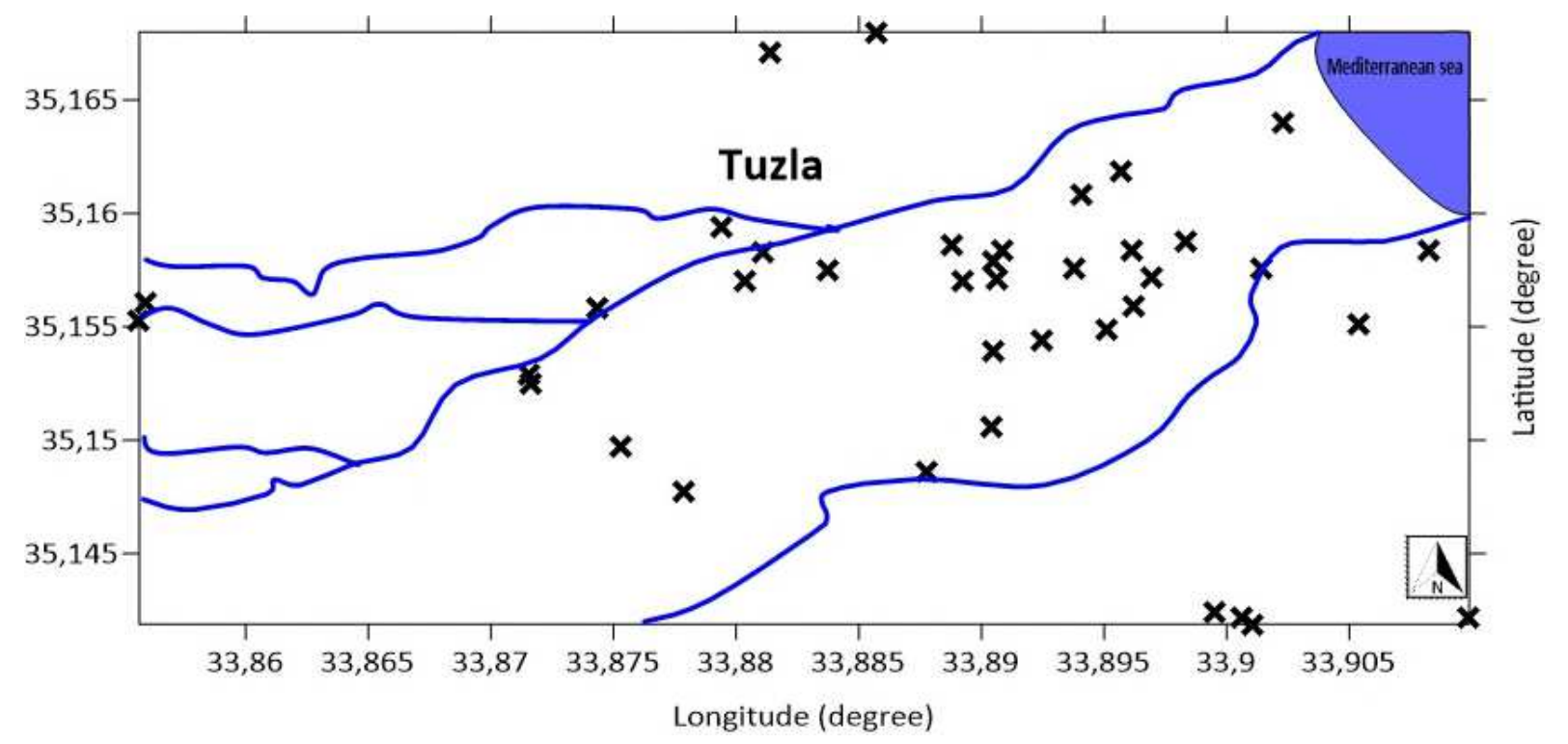




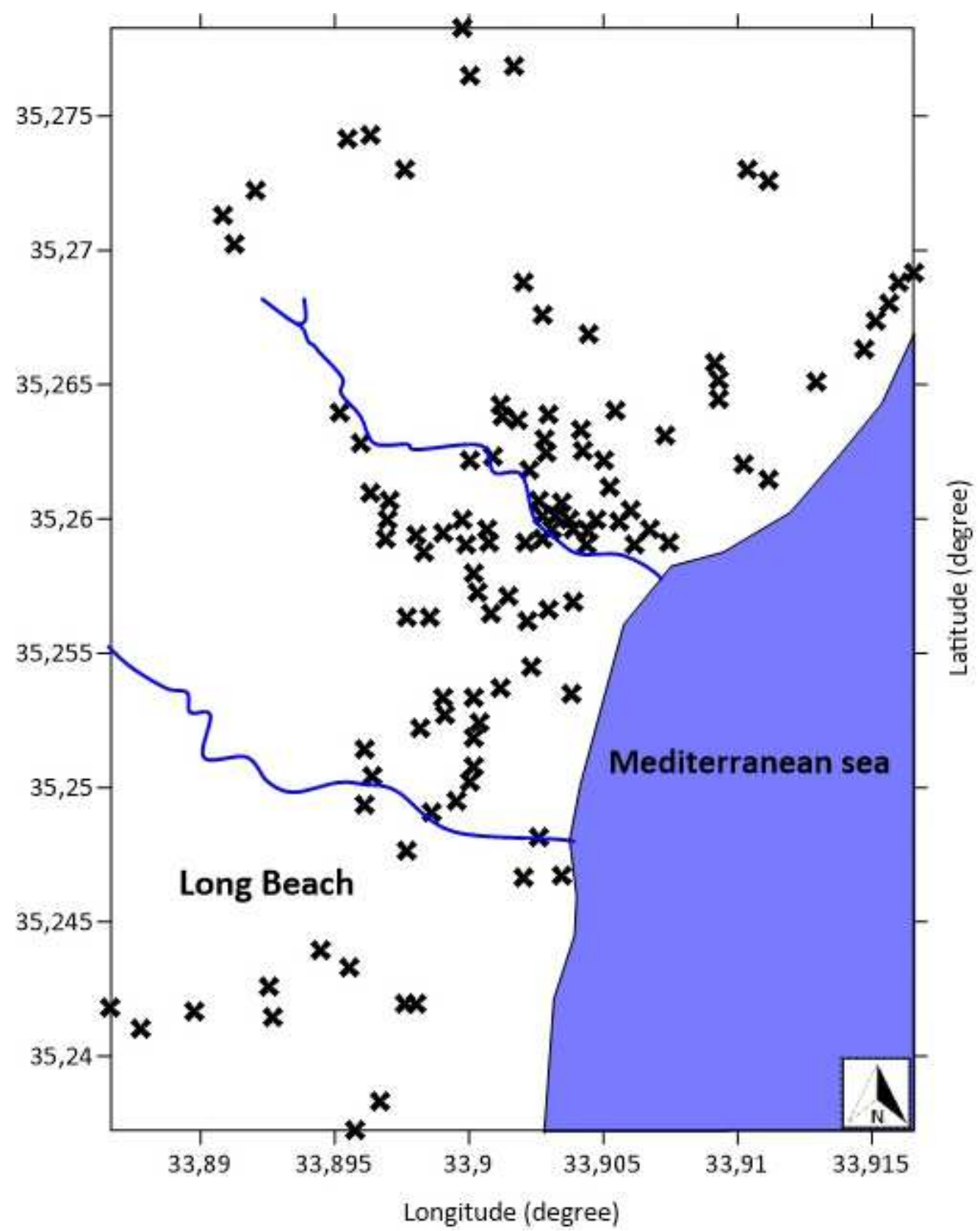



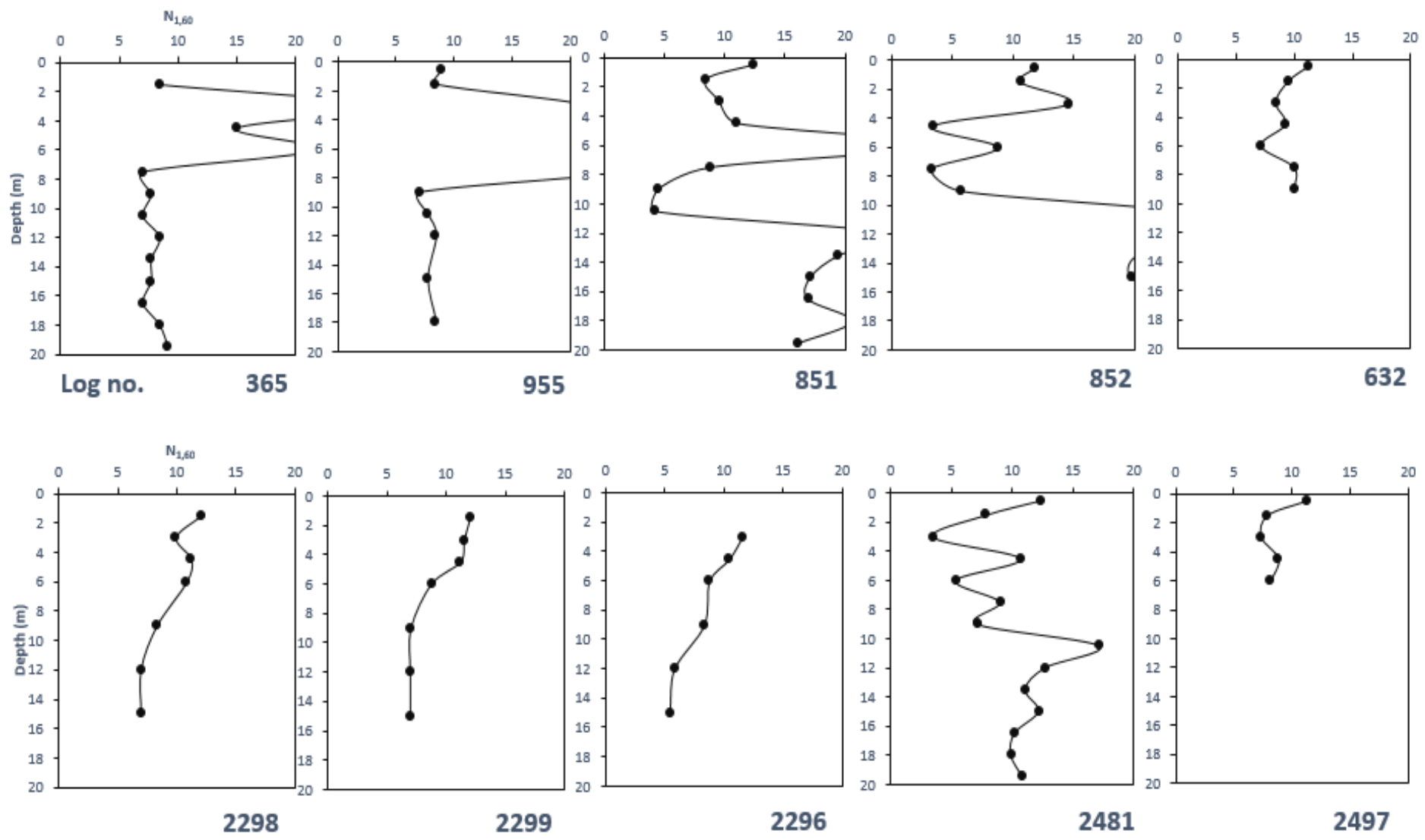

Figure 6. Risky boreholes against liquefaction corrected SPT blow counts from the Long Beach area 

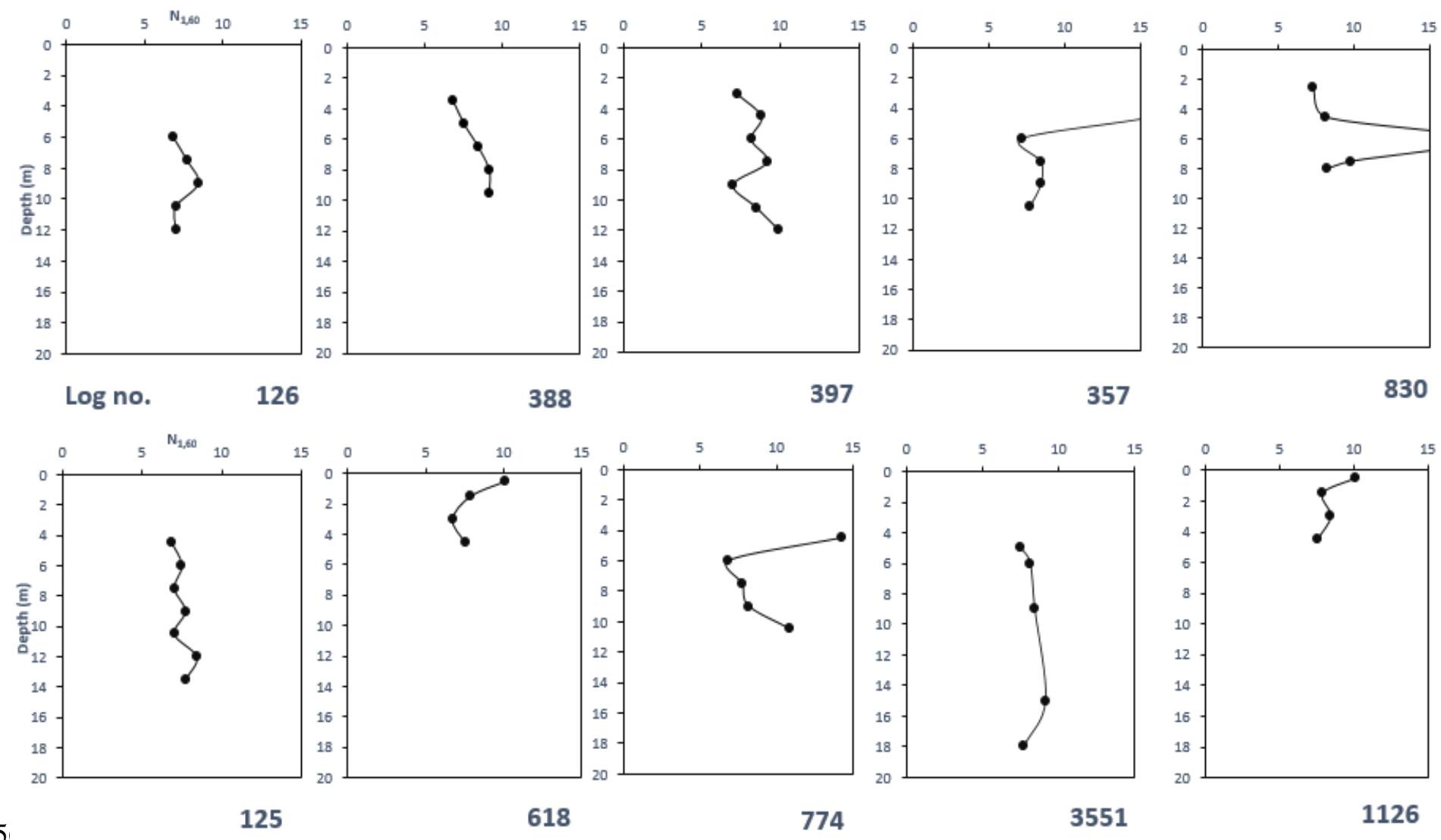

Figure 7. Risky boreholes against liquefaction corrected SPT blow counts from the Tuzla area.

567

568

569

570

571

572

573

574

575

576

577 


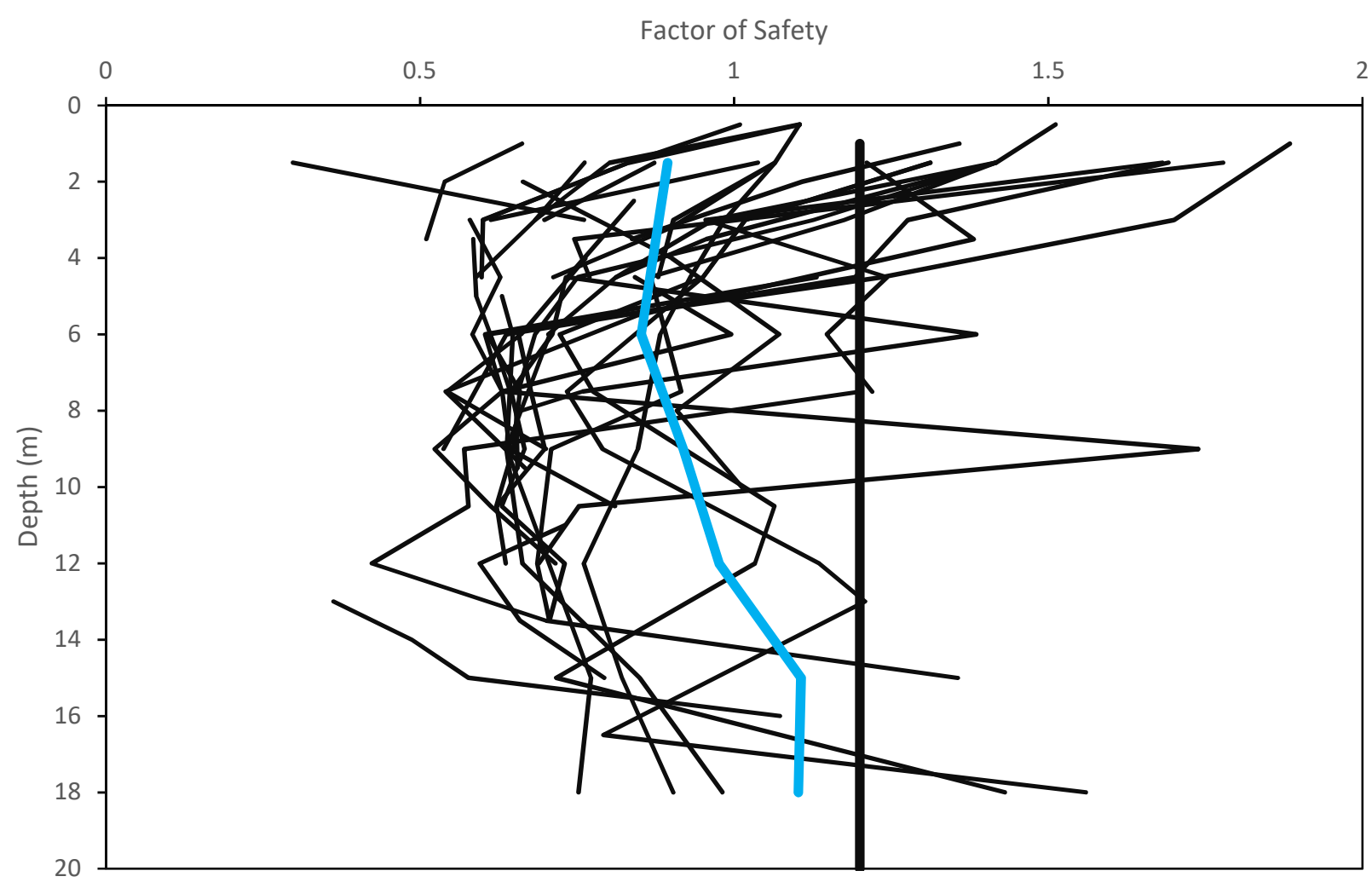




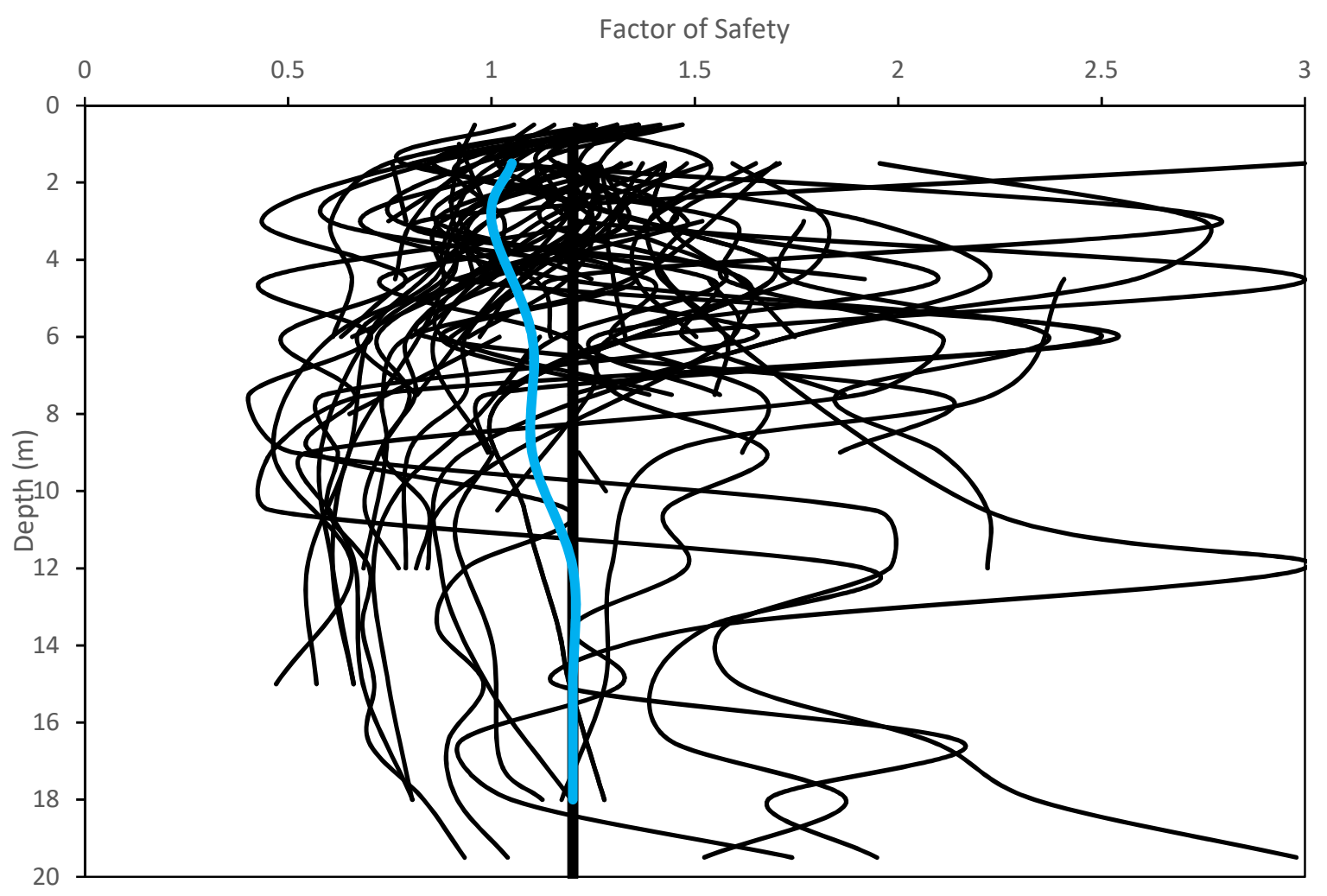

598 
608

609

610

611

612

613
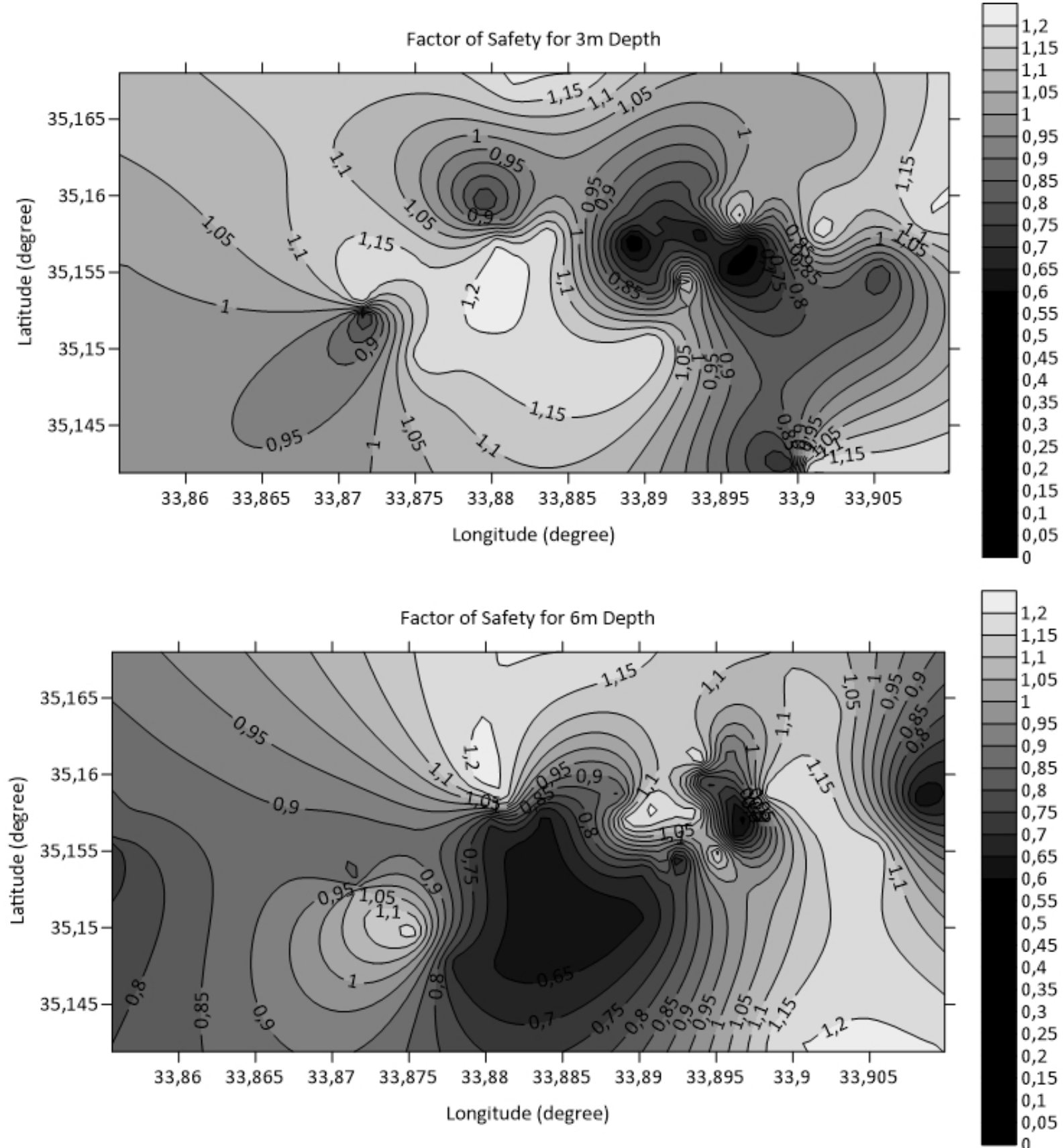
616

617

618

619

620

621

622

623

624

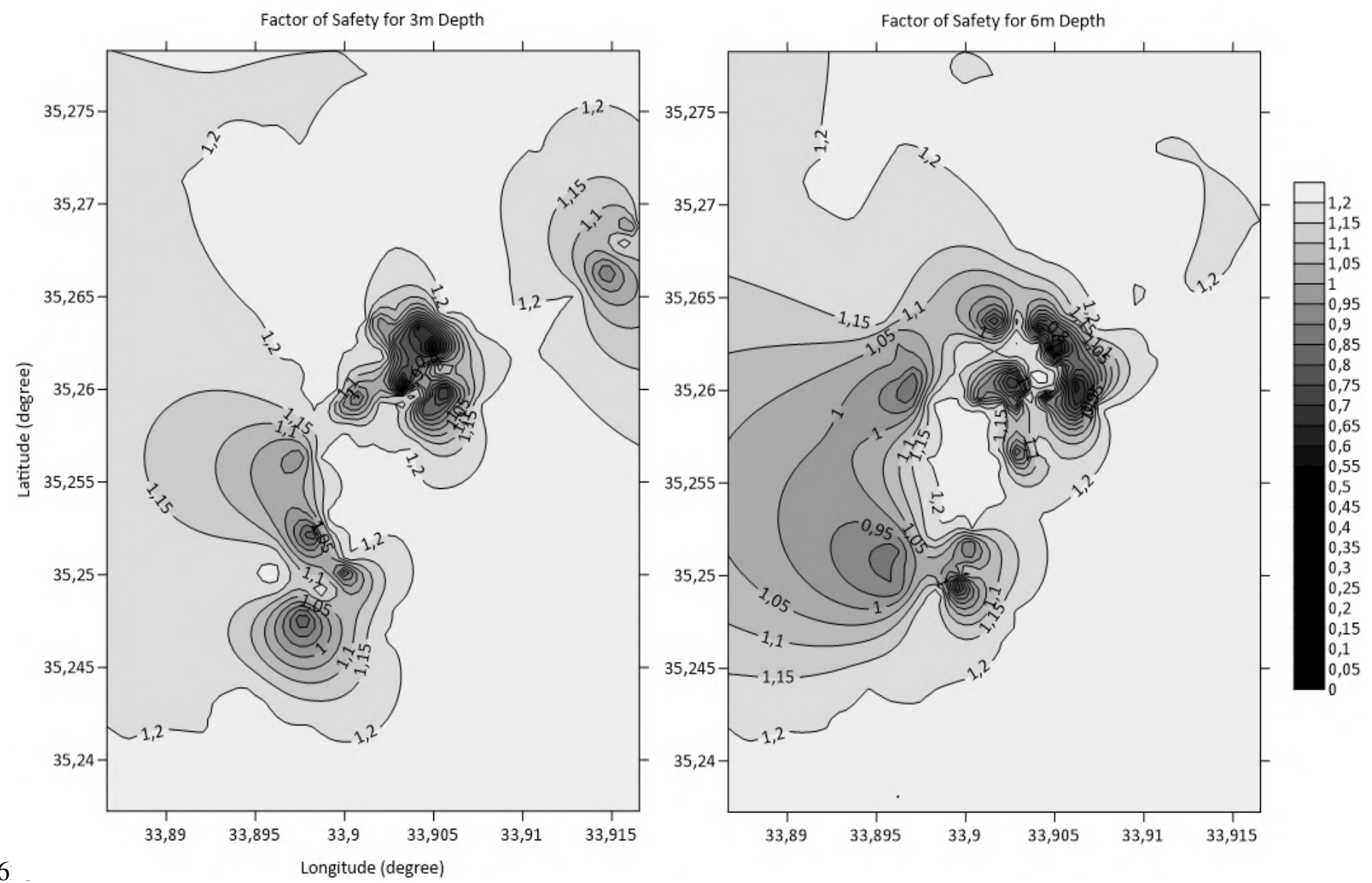

Figure 11. FS distribution of the Long Beach area up to 6m depth 
630

631

632

633

634

635

636

637

638

639

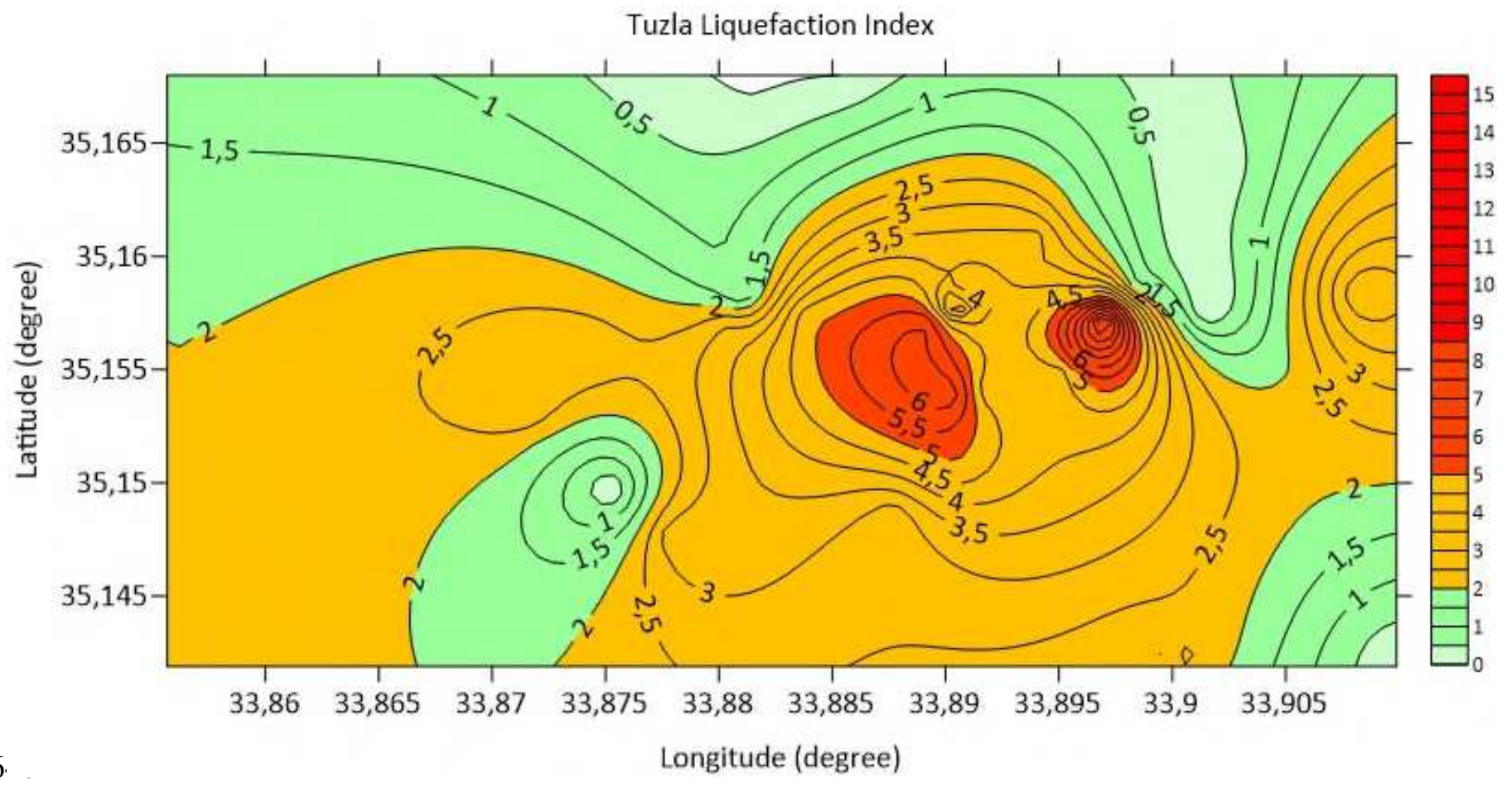


648

649

650

651

652

653

654

655

656

657

658

659 


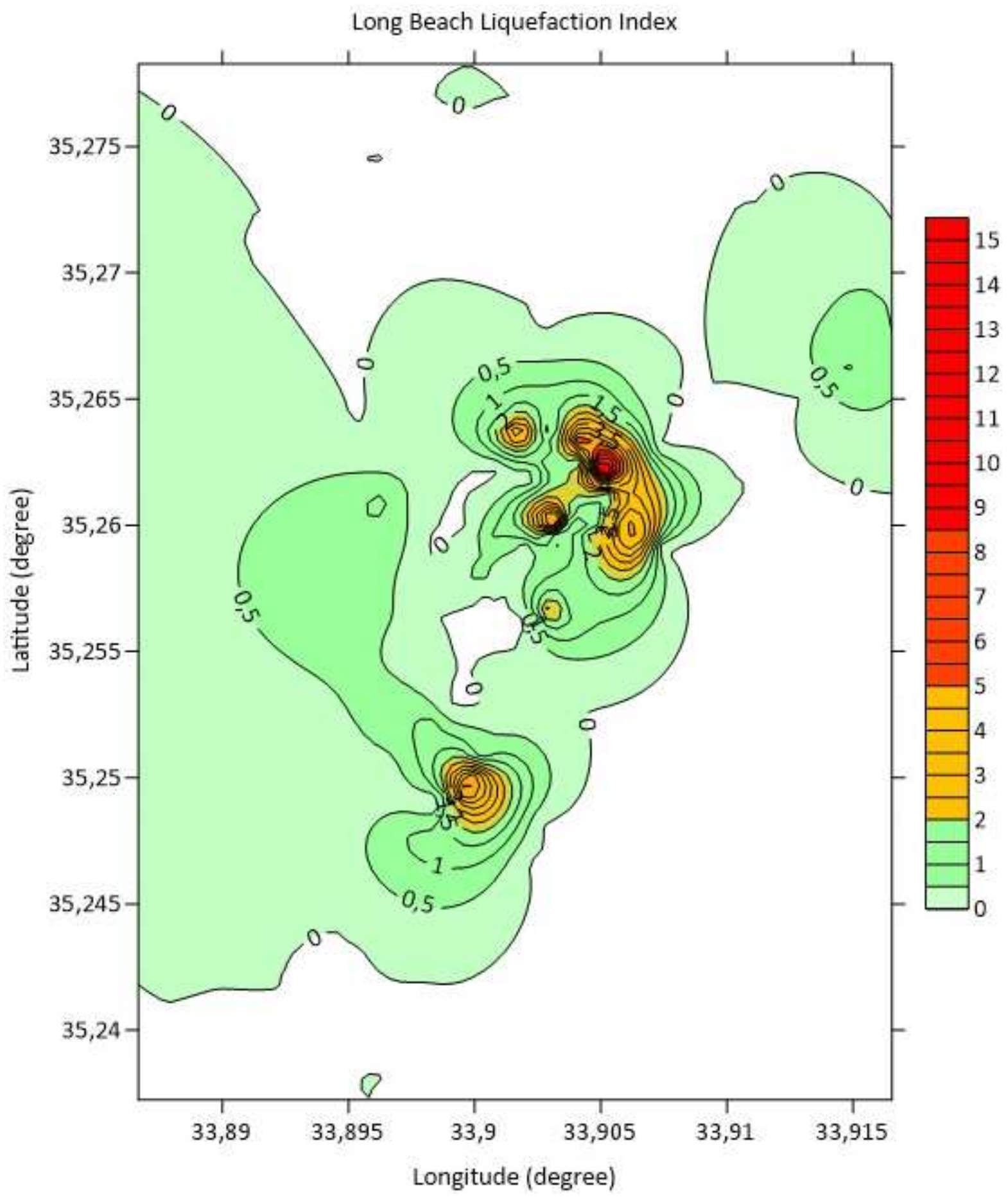

660

Figure 13. Liquefaction risk index map of the Long Beach area

662

663

664

665

666 


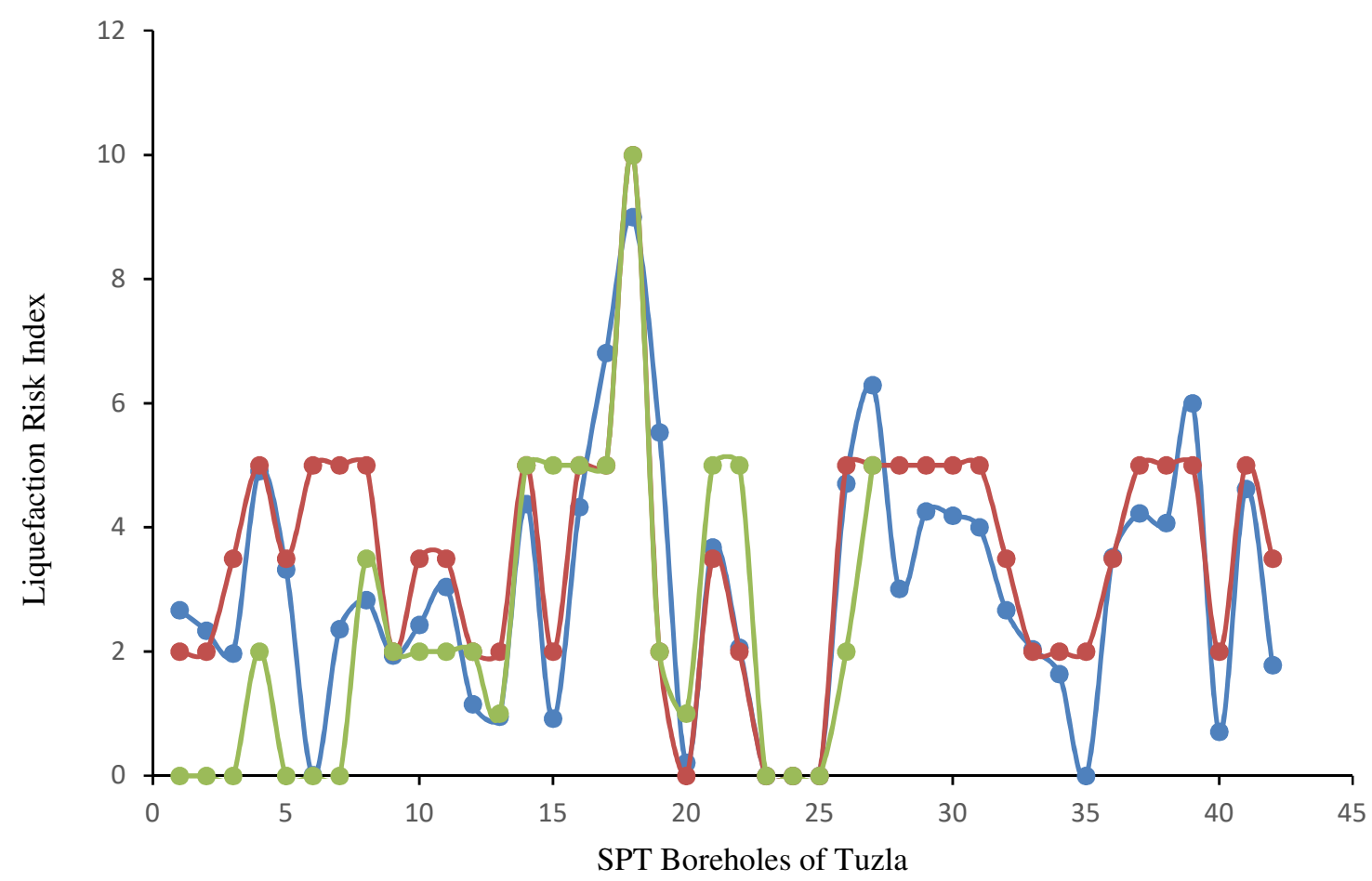

$$
\longrightarrow \text { Selcukhan \& Ekinci (n.d) } \quad \longrightarrow \text { Cetin (2009) } \quad \longrightarrow \text { Biryılmaz (2009) }
$$

Figure 14 Liquefaction risk index comparison of the Tuzla 